\title{
KEANEKARAGAMAN JENIS VEGETASI TINGKAT POHON DI HUTAN ADAT GUNUNG SOKA DUSUN PADANG SEBATIK KECAMATAN AIR BESAR KABUPATEN LANDAK
}

\author{
(Diversities Of Vegetation Types Of Tree In Soka Mountain Indigenous Forest Of Dusun \\ Padang Sebantik Of Air Besar District Of Landak Regency)
}

\author{
Tarsius, Gusti Hardiansyah, Harnani husni \\ Fakultas Kehutanan Universitas Tanjungpura Pontianak. Jl. Daya Nasional Pontianak 78124 \\ Email : tarsisius.tatar@yahoo.co.id
}

\begin{abstract}
Forest is an ecosystem unit in the form of a stretch of land containing biological natural resourcesdominated by trees in its natural environment which can not be separated from the life of indigineous communities. This study aims to find out the diversity of vegetation types of stand composition trees in Gunung Soka Indigenous Forest. This study used transect method and the transect lineswere determined purposively. There were 4 (four) transect lines with $500 \mathrm{~m}$ lenght, $10 \mathrm{~m}$ wide to the left and $10 \mathrm{~m}$ wide to the right. The observation plot was $20 \mathrm{~m}$, and there were 25 plots, so the total was 1 ha. There were 100 plots to study with 4 transect line so the total area was 4 ha. The result show that there are 23 trees vegetation consists of 13 family, 741 of individual trees in Gunung Soka Indigenous Forest. The highest important value index (INP) was found in engkabang bukit (Shorea pinanga Scheff.) with a value of 82,25, while the lowest important value index was found in keraci (Quercus lucida Roxb.) with a value of 1,42. The Dominance index $(C)$ of trees vegetation is 0,17525 or $C=1$, which shows that there are more than one dominant tree. The Diversity index (DS) of trees vegetation is closte to 1, which shows moderate diversity of species. The Highest species Abundance index (e) of tree vegetation was found in line 1 with a value of 0,9493, meanwhile the lowest value was found in line 2 with a value of 0,5764 .
\end{abstract}

Kata Kunci : Diversity,indigenous forest, tree vegetation

\section{PENDAHULUAN}

Hutan adat jika dilihat menurut Undang-Undang Republik Indonesia No. 41 tahun 1999 tentang kehutanan adalah hutan negara yang berada dalam wilayah masyarakat hukum adat. Akan tetapi masyarakat yang bertempat tinggal disekitar maupun dalam hutan mengklaim bahwa hutan adat adalah milik mereka dalam artian milik masyarakat adat yang diperoleh dari warisan leluhur mereka sebelum pendudukan pemerintahan Hindia Belanda dan sampai kinipun masih diakui kedudukanya oleh masyarakat Adat lainnya (Susanti, 2011). Hutan bagi masyarakat adat mempunyai peranan yang sangat besar bagi kehidupan masyarakat setempat maupun sekitar hutan karena hutan merupakan sumber kehidupan (Fitrianti, 2012).

Kawasan hutan adat Gunung Soka berpotensi untuk dikembangkan sebagai sarana pendidikan dan penelitian. Namun keanekargaman jenis pada hutan adat Gunung Soka belum diketahui komposisi jenisnya, khususnya vegetasi 
pada tegakan pohon.Oleh karena itu diperlukan data dan informasi mengenai keadaan areal hutan meliputi komposisi jenis dari vegetasi yang tumbuh didalamnya, tepatnya kawasan Hutan Adat Gunung Soka di Dusun Padang Sebantik, Kecamatan Air Besar, Kabupaten Landak. Dengan adanya data dan informasi mengenai keanekaragaman jenis vegetasi pohon, akan dapat dimanfaatkan dan dikembangkan lebih lanjut lagi bagi pengelolaan hutan adat itu sendiri, serta masyarakat setempat dapat memanfaatkanya secara optimal

Tujuan dan manfaat penelitian yaitu mengetahui keanekaragaman jenis vegetasi tingkat pohon penyusun tegakan serta menganalisis dan mendiskripsikan jenis Vegatasi tingkat pohon penyusun tegakan dalam kawasan hutan Adat Gunung Soka.Sehingga dapat menjadi acuan dalam pengelolaan serta pemanfaatan oleh masyarakat dan pemerintah setempat.

\section{METODE PENELITIAN}

Penelitian ini akan dilaksanakan di Hutan Adat Gunung Soka Dusun Padang Sebantik, Kecamatan Air Besar, Kabupaten Landak dengan waktu pelaksanaan kurang lebih 4 Minggu.Metode jalur yaitu dengan penentuan jalur pengamatan yang dilakukan secara purposive dengan pertimbangan melihat komposisi jenis dan kondisi hutan setelah dilakukan orientasi lapang terlebih dahulu agar data yang teramati dapat benar- benar representatif. Jalur pengamatan dibuat sebanyak 4 jalur, setiap jalur memilki panjang $500 \mathrm{~m}$ dengan lebar ke kiri 10 $\mathrm{m}$ dan kanan $10 \mathrm{~m}$, sehingga luas petak pengamatan berukuran $20 \mathrm{~m}$, dan masing- masing jalur terdapat 25 petak dengan luas total pengamatan setiap jalur 1 ha. Petak yang diteliti sebanyak 100 petak dengan 4 jalur pengamatan, memilki luas keseluruhan yaitu 4 ha. Alat dan bahan yang digunakan untuk menunjang pelaksanaan penelitian antara lain adalah peta lokasi penelitian, kompas,tali, meteran, tongkat ukur, phy-band, parang, buku pedoman pengenalan pohon, alat untuk membuat herbarium (kertas koran, karton tebal, pisau silet,isolasi, label, plastik pacing, alkohol $70 \%$.) kamera,GPS.

Data yang telah diperoleh dari kegiatan pengamatan dilapangan kemudian diolah dengan menghitung Indeks Nilai Penting (INP). Indeks nilai penting (INP) ini digunakan untuk menetapkan dominansi suatu jenis terhadap jenis lainnya atau dengan kata lain nilai penting menggambarkan kedudukan ekologis suatu jenis dalam komunitas.

Indeks Nilai Penting

Indeks Nilai Penting berguna untuk menentukan dominasi suatu jenis terhadap jenis lainnya dalam suatu tegakan dengan rumus (Soerianegara dan Indrawan, 1976):

$\mathrm{INP}=\mathrm{KR}+\mathrm{FR}+\mathrm{DR}$

a) Kerapatan ( K ) = $\frac{\text { JumlahIndividuSuatuJenis }}{\text { LuasContoh }}$

b) kerapatan Relatif ( KR ) $=\frac{\text { KerapatanSuatuJenis }}{\text { KerapatanseluruhJenis }} \times 100 \%$ 
c) Frekuensi (F) $=\frac{\text { JumlahPetakditemukansuatuJenis }}{\text { JumlahSeluruhPetakPengamatan }}$

d) frekuensi Relatif ( FR )

$$
=\frac{\text { Frekuensisuatujenis }}{\text { frekuensiseluruhjenis }} \times 100 \%
$$

e) Dominasi ( D ) = JumlahLuasBidangDasar LuasSeluruhPetakcontoh

f) Dominasi Relatif ( DR ) = $\frac{\text { DominasiSuatuJenis }}{\text { DominasiSeluruhJenis }}$ X 100\%

Indeks Dominasi (C)

Indeks Dominansi dihitung untuk menetukan dominansi dalam suatu komunitas dari suatu jenis. Rumus untuk menentukan dimana dominasi dipusatkan menggunakan rumus (Simpson dalam Budhi, 2007 ) sebagai berikut :

$\mathrm{C}=\sum \frac{\mathrm{ni}(\mathrm{ni}-1)}{\mathrm{N}(\mathrm{N}-1)}$

Dimana :

$\mathrm{C}=$ Indeks Dominasi

$\mathrm{ni}=$ Jumlah Individu dari spesies 1

$\mathrm{N}=$ Jumlah individu dari semua jenis

Indeks Keanekaragaman Jenis ( DS )

Indeks Keanekaragaman Jenis ( DS

Indeks keragaman jenis (Spesies

Diversity Index) adalah suatu indeks keragaman secara keseluruhan dalam suatu tipe hutan, yang dapat ditentukan dengan rumus Shannon - Winner :

$\mathrm{DS}=-\Sigma \frac{n i}{N} \log \frac{n i}{N}$
Dimana :

DS = Indeks keanekaragaman Shannon

\& Winner

ni $=$ Jumlah individu suatu jenis

$\mathrm{N}=$ Jumlah total individu seluruh jenis

Kriteria indeks keanekaragaman dibagi

dalam 3 kategori yaitu :

1. $<1$ tergolong rendah

2. 1 - 3 tergolong sedang

3. > 3 tergolong tinggi

Indeks Keimpahan Jenis ( e )

Indeks Keimpahan Jenis ( e )Indeks kelimpahan jenis dipengaruhi oleh keanekaragaman jenis dan jumlah jenis digunakan untuk mengetahui kelimpahan suatu jenis area atau pada suatu ukuran contoh tertentu. Untuk itu dipergunakan rumus ( Soerinegara dan Indrawan, 1978 ).

$\mathrm{e}=\mathrm{DS} / \log \mathrm{S}$

Dimana :

$\mathrm{e}=$ Indeks Kelimpahan Jenis

DS = Indeks keanekaragaman jenis

$\mathrm{S}=$ Jumlah dari jenis

\section{HASIL DAN PEMBAHASAN}

Hasil penelitianpada kawasan Hutan Adat Gunung Soka ditemukan sedikitnya 23 jenis vegetasi tingkat pohon terdiri dari 13 family yang berbeda.Penelitian dilakukan dengan membuat jalur pengamatan sebanyak 4(empat) jalur dengan luas total petak pengamatan kurang lebih 4 hektar. 
Tabel 1.Indeks Nilai Penting (INP) Semua Jalur (The Index Value All Paths)

\begin{tabular}{|c|c|c|c|c|c|c|}
\hline \multirow[t]{2}{*}{ No } & \multirow{2}{*}{$\begin{array}{l}\text { Nama } \\
\text { Lokal }\end{array}$} & \multirow{2}{*}{$\begin{array}{l}\text { Nama Jenis } \\
\text { Latin }\end{array}$} & \multicolumn{4}{|c|}{ INP Semua Jalur $=\mathrm{KR}+\mathrm{FR}+\mathrm{DR}$} \\
\hline & & & Jalur 1 & Jalur 2 & Jalur 3 & Jalur 4 \\
\hline 1 & Bengkirai & Shorea laevisRidl. & 28,20 & 26,55 & 30,03 & 24,67 \\
\hline 2 & Durian & Durio zibethinusL. & - & 3,82 & 13,16 & 13,93 \\
\hline 3 & Engkabang Bukit & Shorea pinanga Scheff. & 82,25 & 72,42 & 59,26 & 50,17 \\
\hline 4 & Gaharu & Aquilariamalaccensis Lam. & - & 0,93 & - & - \\
\hline 5 & Gandaria & Bouea macrophyllaGriff. & 7,93 & 7,39 & 5,75 & 4,18 \\
\hline 6 & Jelutung & Dyera costulata (Miq.) Hook. & 2,78 & 3,62 & 15,20 & 13,29 \\
\hline 7 & Kahui/Balangeran & Shorea balangeran Burck & 33,73 & 25,69 & 24,45 & 16,52 \\
\hline 8 & Kayu asem & Tetrameristaglabra Miq. & 25,29 & 17,66 & 13,04 & 16,26 \\
\hline 9 & Keladan & Dryobalanops beccarii Dyer & - & 6,25 & 6,36 & 9,07 \\
\hline 10 & Kelampai & Elateriospermum taposBlume & 12,91 & 7,87 & 6,56 & 8,33 \\
\hline 11 & Kempas & Koompassia malaccensisBenth. & - & - & 6,01 & 9,75 \\
\hline 12 & Keraci & Quercus lucida Roxb. & - & 1,42 & 3,97 & 4,86 \\
\hline 13 & Keranji & Dialium $s p$ & 3,89 & 3,68 & 4,73 & 10,03 \\
\hline 14 & Manggis Hutan & Garcinia bancanaMiq. & 7,90 & 7,36 & 7,17 & 5,13 \\
\hline 15 & Medang & Litsea sp & & 4,19 & 3,91 & 3,82 \\
\hline 16 & Melaban & Tristania $s p$ & - & 2,26 & - & 1,91 \\
\hline 17 & Meranti balau & Shorea seminisSlooten & 75,80 & 71,91 & 50,47 & 42,58 \\
\hline 18 & Meranti merah & Shorea pilosaP.S.Ashton & 19,32 & 12,68 & 5,99 & 6,95 \\
\hline 19 & Nyatoh & Palaquim rostratum(Miq.) Burk & - & 6,22 & 8,87 & 10,01 \\
\hline 20 & Nyatu Gagas & Palaquium cochleariifolium P.Royen & - & 8,64 & 17,05 & 18,31 \\
\hline 21 & Petai Padi & Parkia singularisMiq. & - & 1,88 & 1,83 & 3,21 \\
\hline 22 & Pulai & Alstonia scholaris $(\mathrm{L}.) \mathrm{R} . \mathrm{Br}$. & - & - & 6,87 & 14,80 \\
\hline 23 & Tekam & Hopea sp & - & 7,58 & 9.32 & 12.20 \\
\hline & Total & & 300,00 & 300,00 & $\mathbf{3 0 0 , 0 0}$ & 300,00 \\
\hline
\end{tabular}

Sumber : Analisis Data, 2016

Tabel 1menunjukan bahwa jenis engkabang bukit (Shorea pinanga) merupakan jenis yang memiliki INP paling besar pada setiap jalur pengamatan, yaitu jalur 1 (INP 82,25), jalur 2 (INP 72,42), jalur 3 (INP 59,26) dan jalur 4 (INP 50,17). Sementara INP paling kecil, untuk jalur 1 terdapat pada jenis jelutung (Dyera costulata) (INP 2,78), jalur 2 terdapat pada jenis gaharu (Aquilaria malaccensis) (INP 0,93),jalur 3 terdapat pada jenis petai padi (Parkia singilaris) (INP 1,83)dan jalur 4 terdapat pada jenis melaban (Tristania $s p$ ) (INP 1,91). 
Tabel 2. Indeks Dominasi (C) (Dominance Index)

\begin{tabular}{|c|c|c|c|c|c|c|}
\hline \multirow[t]{2}{*}{ No } & \multirow{2}{*}{$\begin{array}{l}\text { Nama } \\
\text { Lokal }\end{array}$} & \multirow{2}{*}{$\begin{array}{l}\text { Nama Jenis } \\
\text { Latin }\end{array}$} & \multicolumn{4}{|c|}{ Indek Dominasi (C) } \\
\hline & & & Jalur 1 & Jalur 2 & Jalur 3 & Jalur 4 \\
\hline 1 & Bengkirai & Shorea laevisRidl. & 0,00884 & 0,00783 & 0,01002 & 0,00676 \\
\hline 2 & Durian & Durio zibethinusL. & - & 0,00016 & 0,00192 & 0,00216 \\
\hline 3 & Engkabang bukit & Shorea pinanga Scheff. & 0,07517 & 0,05827 & 0,03902 & 0,02797 \\
\hline 4 & Gaharu & Aquilariamalaccensis Lam. & - & 0,00311 & - & - \\
\hline 5 & Gandaria & Bоиеатасrophylla Griff. & 0,00070 & 0,00061 & 0,00037 & 0,00019 \\
\hline 6 & Jelutung & Dyera costulata (Miq.) Hook. & 0,00008 & 0,00015 & 0,00257 & 0,00196 \\
\hline 7 & Kahui/Balangeran & Shorea balangeranBurck & 0,01264 & 0,00733 & 0,00664 & 0,00303 \\
\hline 8 & Kayu asem & Tetramerista glabra Miq. & 0,00711 & 0,00346 & 0,00189 & 0,00294 \\
\hline 9 & Keladan & Dryobalanops beccarii Dyer & - & 0,00043 & 0,00045 & 0,00091 \\
\hline 10 & Kelampai & Elateriospermum taposBlume & 0,00185 & 0,00069 & 0,00048 & 0,00077 \\
\hline 11 & Kempas & Koompassia malaccensisBenth. & - & & 0,00040 & 0,00077 \\
\hline 12 & Keraci & Quercus lucida Roxb. & - & 0,00002 & 0,00018 & 0,00026 \\
\hline 13 & Keranji & Dialium $s p$ & 0,00017 & 0,00015 & 0,00025 & 0,00112 \\
\hline 14 & Manggis Hutan & Garcinia bancana Miq. & 0,00069 & 0,00060 & 0,00057 & 0,00029 \\
\hline 15 & Medang & Litsea $s p$ & - & 0,00020 & 0,00017 & 0,00016 \\
\hline 16 & Melaban & Tristania $s p$ & - & 0,00006 & - & 0,00020 \\
\hline 17 & Meranti balau & Shorea seminisSlooten & 0,06385 & 0,05745 & 0,02830 & 0,02015 \\
\hline 18 & Meranti merah & Shorea pilosa P.S.Ashton & 0,00415 & 0,00179 & 0,00040 & 0,00054 \\
\hline 19 & Nyatoh & Palaquim rostratum(Miq.) Burk & - & 0,00043 & 0,00087 & 0,00111 \\
\hline 20 & Nyatu Gagas & Palaquium cochleariifolium P.Royen & - & 0,00083 & 0,00323 & 0,00373 \\
\hline 21 & Petai Padi & Parkia singularisMiq. & - & 0,00004 & 0,00004 & 0,00011 \\
\hline 22 & Pulai & Alstonia scholaris(L.) R. Br. & - & & 0,00052 & 0,00243 \\
\hline \multirow[t]{2}{*}{23} & Tekam & Hopea $s p$ & - & 0,00064 & 0,00097 & 0,00165 \\
\hline & Total & & 0,17525 & 0,14424 & 0,09925 & 0,07952 \\
\hline
\end{tabular}

Sumber : Analisis Data, 2016

Tabel 2 menunjukan, indeks dominasi paling besar pada jalur 1 terdapat pada jenis engkabang bukit ( Shorea pinanga ) (C 0,07517), sementara indek dominasi paling kecil terdapat pada jenis jelutung ( Dyera costulata) (C 0,00008). Jalur 2, indek dominasi besar terdapat pada jenis Engkabang bukit ( Shorea pinanga (C 0,05827), sementara indeks dominasi paling kecil terdapat pada jenis Keraci (
Quercus Lucida.Roxb ) (C 0,00002). Jalur 3, indek dominasi besar terdapat pada jenis Engkabang bukit ( Shorea pinanga (C 0,03902) sementara indeks dominasi paling kecil terdapat pada jenis Petai padi (C 0,00004) Jalur 4, indek dominasi besar terdapat pada jenis Engkabang bukit ( Shorea pinanga ) (C 0,02797), sementara indeks dominasi paling kecil terdapat pada jenis Petai padi (C 0,00011). 
Tabel 3. Indeks keanekaragaman Jenis (DS) (Species Diversity Index)

\begin{tabular}{|c|c|c|c|c|c|c|}
\hline \multirow[t]{2}{*}{ No } & \multirow{2}{*}{$\begin{array}{l}\text { Nama } \\
\text { Lokal }\end{array}$} & \multirow{2}{*}{$\begin{array}{c}\text { Nama Jenis } \\
\text { Latin }\end{array}$} & \multicolumn{4}{|c|}{ Indeks Keanekaragaman jenis (DS) } \\
\hline & & & Jalur 1 & Jalur 2 & Jalur 3 & Jalur 4 \\
\hline 1 & Bengkirai & Shorea laevisRidl. & 0,869 & 0,886 & 0,878 & 0,905 \\
\hline 2 & Durian & Durio zibethinusL. & - & 0,995 & 0,972 & 0,965 \\
\hline 3 & Engkabang Bukit & Shorea pinanga Scheff. & 0,731 & 0,762 & 0,801 & 0,830 \\
\hline 4 & Gaharu & Aquilaria malaccensis Lam. & - & 0,995 & - & . \\
\hline 5 & Gandaria & Bouea macrophylla Griff. & 0,954 & 0,962 & 0,967 & 0,970 \\
\hline 6 & Jelutung & Dyera costulata (Miq.) Hook. & 0,989 & 0,984 & 0,956 & 0,960 \\
\hline 7 & Kahui/Balangeran & Shorea balangeran Burck & 0,903 & 0,924 & 0,928 & 0,945 \\
\hline 8 & Kayu Asem & Tetrameristaglabra Miq. & 0,949 & 0,962 & 0,972 & 0,965 \\
\hline 9 & Keladan & Dryobalanops beccarii Dyer & - & 0,973 & 0,983 & 0,970 \\
\hline 10 & Kelampai & Elateriospermum taposBlume & 0,891 & 0,930 & 0,945 & 0,935 \\
\hline 11 & Kempas & Koompassia malaccensisBenth. & - & - & 0,983 & 0,970 \\
\hline 12 & Keraci & Quercus lucida Roxb. & - & 0,984 & 0,972 & 0,970 \\
\hline 13 & Keranji & Dialium $s p$ & 0,983 & 0,984 & 0,972 & 0965 \\
\hline 14 & Manggis Hutan & Garcinia bancana Miq. & 0,960 & 0,962 & 0,961 & 0,970 \\
\hline 15 & Medang & Litsea $s p$ & - & 0,968 & 0,961 & 0,970 \\
\hline 16 & Melaban & Tristania $s p$ & - & 0,989 & - & 0,990 \\
\hline 17 & Meranti balau & Shorea seminisSlooten & 0,834 & 0,859 & 0,901 & 0,920 \\
\hline 18 & Meranti merah & Shorea pilosa P.S.Ashton & 0,937 & 0,962 & 0,978 & 0,970 \\
\hline 19 & Nyatoh & Palaquim rostratum(Miq.) Burk & - & 0,984 & 0,972 & 0,970 \\
\hline 20 & Nyatu Gagas & Palaquium cochleariifolium P.Royen & - & 0,978 & 0,961 & 0,960 \\
\hline 21 & Petai Padi & Parkia singularisMiq. & - & 0,989 & 0,989 & 0,980 \\
\hline 22 & Pulai & Alstonia scholaris(L.) R. Br. & - & - & 0,983 & 0,665 \\
\hline 23 & Tekam & Hopea $s p$ & - & 0,968 & 0,961 & 0,955 \\
\hline & Total & & 0,909 & $\mathbf{0 , 9 5 2}$ & 0,952 & 0,955 \\
\hline
\end{tabular}

Sumber : Analisis Data, 2016

Tabel 3 menujukan bahwa, indeks keanekaragaman jenis (DS) paling besar pada jalur 1 terdapat pada Jelutung (Dyeracostulata) (DS 0,989), sementara indek keanekaragaman jenis paling kecil terdapat pada Engkabang Bukit ( Shorea pinanga ) (DS 0,731). Jalur 2, indek keanekaragaman jenis besar terdapat pada Durian (Duriozibethinus ) (DS 0,995), sementara indeks keanekaragaman jenis paling kecil terdapat pada Engkabang Bukitt ( Shorea pinanga) (DS 0,762). Jalur 3, indek keanekaragaman jenis paling besar terdapat pada Petai padi ( Parkia singilaris ) (DS 0,989). sementara indeks keanekaragaman jenis paling kecil terdapat pada Engkabang Bukitt ( Shorea pinanga ) (DS 0,801). Jalur 4, indek keanekaragaman jenis besar terdapat pada Medang ( Litsea sp ) (DS 0,990), sementara indeks keanekaragaman jenis paling kecil terdapat pada Engkabang Bukitt ( Shorea pinanga ) (DS 0,830).

Hasil penelitian di hutan adat Gunung Soka menggambarkan bahwa struktur dan komposisi tumbuhan tingkat pohon pada kawasan tersebut cukup bervariasi. Berdasarkan pengamatan yang dilakukan, sedikitnya ditemukan 23 jenis vegetasi tingkat pohon dari 13 family yang 
berbeda. Jumlah total individu hasil inventarisasi di lapangan diperoleh sebanyak 741 individu pohon.

Dari jenis-jenis pohon yang ditemukan, beberapa diantaranya memiliki nilai ekonomi dan berpotensi cukup tinggi seperti durian (Durio zibethinusL.) buahnya punya nilai jual yang cukup tinggi, gaharu (Aquilaria malaccensisLam.) jenis pohon ini memiliki nilai jual yang tinggi, pulai (Alstonia scholaris(L.) R. Br.) masyarakat setempat menggunakannya untuk berbagai keperluan seperti kayu bakar dan bahan bangunan. Akibat dari memiliki nilai ekonomi dan manfaat yang tinggi maka jenis-jenis pohon yang didapati pada hutan adat semakin berkurang dan menurut data yang didapat berdasarkan daftar IUCN Red List, ada beberapa jenis yang masuk dalam kategori terkikis /hampir terancam dan rawan atau rentan. Antara lainnya yang hampir terancam (least concern) adalah jenis pulai (Alstonia scholaris (L.) R. Br.), sedangkan untuk jenis gaharu (Aquilaria malaccensisLam.) masuk kategori rawan (vulnerable). Kedua kriteria tersebut memilki pengertian yang berbeda, apabila berada dalam keterancaman atau mendekati ancaman kepunahan namun tidak masuk ke status terancam istilah dalam IUCN yaitu Near Threatened (NT) atau hampir terancam, apabila menghadapi resiko punah di alam liar di waktu mendatang istilah dalam IUCN yaitu vulnerable (VU) atau rawan (Anonim, 2013).

Indriyanto (2008) mengemukakan, bahwa hutan hujan bawah memilki ketinggian dari $0-1.000 \mathrm{~m}$ dpl yang mana dapat dijumpainya jenis-jenis pohon dari famili Dipterocarpacea, Myrtaceae, serta beberapa jenis Koompassia. Jenis pohon yang ditemukan pada areal penelitian Hutan Adat Gunung Soka adalah jenisjenis yang ditemukan pada hutan hujan bawah, dengan ketinggian $\pm 250 \mathrm{~m} \mathrm{dpl}$ berdasarkan data dilapangan.

Faktor biotik (kondisi vegetasi) merupakan faktor yang perlu diperhatikan dalam ekologi hutan karena faktor biotik berperan dan berpengaruh terhadap faktor abiotik. Berdasarkan hasil analisa vegetasi, menunjukan adanya perbedaan jumlah individu dari semua jenis pada tingkat pohon untuk jalur pengamatan, hal ini terjadi disebabkan olehfaktor habitat yang berpengaruh seperti kesempatan dalam mendapatkan cahaya matahari yang optimal dan ketersediaan serta kemampuan penyerapan hara tanah.

\section{Indeks Nilai Penting (INP)}

Indeks nilai penting adalah hasil penjumlahan dari keraatan relative (KR), frekuensi relative (FR) dan dominansi relatif (DR).Selain itu juga indeks nilai penting juga digunakan untuk menentukan dominasi suatu jenis terhadap jenis-jenis lainya dalam suatu tegakan pada setiap tahap atau tingkatan pertumbuhan (Soerianegara dan Indrawan dalam Alhani, 2015).

Berdasarkan analisis data pengamatan di jalur I, II, III dan IV diperoleh bahwa jenis engkabang bukit (Shorea pinangaScheff.) adalah jenis yangmemiliki penguasaan yang lebih besar terhadap tempat tumbuh dibandingkan jenis lainnya. Jenis ini pada jalur pengamatan 1 (satu) memiliki INP 
paling besar dengan nilai sebesar 82,25. Sementara INP terendah terdapat pada jenis keraci (Quercus lucida Roxb.), yang terdapat pada jalur pengamatan 2 dengan nilai 1,42

\section{Indeks Dominasi (C)}

Indeks Dominansi (indeks simpson) digunakan untuk menyatakan tingkat terpusatnya dominansi (penguasaan) spesies dalam suatu komunitas. Dalam indeks simpson ada beberapa kriteria dalam menentukan nilai indeks dominansi, yaitu $\mathrm{C}=0$ dominansi rendah, artinya tidak terdapat spesies yang mendominasi spesies lainya sedangkan $\mathrm{C}=1$ dominansi tinggi, artinya terdapat spesies yang mendominasi jenis spesies yang lainya (Ariyanto

dalam

Agustian,2015).Berdasarkan analisis hasil pengamatan jalur I, II, III, dan IV diperoleh bahwa nilai indeks dominasi (C) vegetasi pohon pada hutan adat Gunung Soka dari 4 (Empat) jalur pengamatan yang dilakukan secara umum berada pada kategori rendah $(0,07952$ - 0,17525). Artinya, bahwa pada kawasan Hutan Adat Gunung Soka tidak hanya satu jenis saja yang dominan terhadap jenis yang lain sehingga kondisi demikian dapat diartikan bahwa dinamika masyarakat tumbuhan masih terus berjalan sampai pada tahap dimana suatu jenis dapat menguasai daerah tersebut. Disamping itu, kecilnya indeks dominasi pada kawasan hutan adat Gunung Soka menunjukan bahwa di kawasan hutan tersebut dominansi jenisnya tidak hanya dikuasai satu jenis saja tetap masih terdapat beberapa jenis lain yang mendominasi daerah tersebut.

\section{Indeks keanekaragaman jenis (DS)}

Indeks keanekaragaman digunakan untuk mengetahui keanekaragaman jenis daritegakkan hutan menurut Indriyanto dalam Agustian (2014), diketahui bahwa seluruh jalur penelitian memiliki nilai (DS) yang tinggi. Secara umum pada kawasan hutan adat Gunung Soka, jenis yang ditemukan sebagian besar berupa famili Dipterocarpaceae.

Dilihat dari nilai keanekaragaman jenisnya, hasil penelitian di kawasan Hutan Adat Gunung Soka menunjukan bahwa keanekaragaman jenis pada masing-masing jalurmemiliki nilai mendekati 1.Hal ini menunjukan bahwa pada kawasan tersebut memiliki keanekaragaman jenis yang tergolong sedangdikarenakan nilai Indeks Keanekaragaman jenis (DS) berada pada kisaran 1 - 3.Berdasarkan analisis data yang dilakukan pada jalur pengamatan jenis Durian (Durio zibethinusL.) merupakan jenis yang ditemukan pada semua jalur penelitian berdasarkan indeks keanekaragaman (DS) memiliki yang tinggi dibandingkan jenis lainya yang yang terdapat pada jalur pengamatan 2 (Dua) dengan nilai 0,995.Indeks keanekaragaman jenis yang terendah adalah jenis Engkabang Bukit/Shorea pinanga Scheff.) yang terdapat pada jalur 1 dengan nilai sebesar 0,762. Kegiatan pemanfaatanoleh masyarakat lokal (adat)terhadap potensi sumber daya khususnya kayu sebagai bahan bangunan ternyata tidak berpengaruh besar terhadap keanekaragaman jenis dalam kawasan hutan tersebut. Serupa dengan hasil penelitian sebelumnya keanekaragamn jenis pohon dikawasan hutan KHDTK 
Samboja sebesar 1,859 (Alhani, 2015) dan analisa vegetasi hutan di areal hutan kota gunung sari kota singkawang sebesar 1,1 (Agustian, 2014).

Dilihat dari keanekaragaman jenis yang berbeda diketahui bahwa di setiap lokasi penelitian tersebut mempunyai keanekaragaman yangberbeda, hal ini dikarenakan adanya perbedaan jenis penyusun komunitas tumbuhan pada suatu tempat merupakan hasil interaksi dari beberapa faktor, faktor pertama adalah waktu, kenekaragaman jenis dalam suatu komunitas tumbuhan merupakan hasil dari evolusi dan terjadi kemungkinan sistem umpan balik (feedback) pada tingkat keanekaragaman jenis. Faktor kedua adalah adanya heterogenitas ruang, komunitas tumbuhan yang terbentuk sangat dipengaruhi oleh lingkungan yang ada (Maisyaroh, 2010).

\section{Indeks Kelimpahan Jenis (e)}

Indeks kelimpahan jenis (e) merupakan salah satu bagian dari komponen keanekaragaman jenis, seperti yang dikemukakan oleh Odum dalam Agustian (2015) bahwa keanekaragaman jenis itu mempunyai sejumlah komponen yang dapat memberikan reaksisecara berbeda-beda terhadap faktor-faktor geografi atau perkembangan fisik. Besarnya nilai indeks kelimpahan jenis sangat dipengaruhi oleh nilai keanekaragaman jenis dan jumlah jenis.

Berdasarkan analisis data hasil pengamatan pada jalur I, II, III dan IV, Jenis Jelutung (Dyera costulata (Miq.) Hook.)merupakan jenis yang ditemukan pada semua jalur penelitian. Jenis ini memiliki Indeks kelimpahan yang tinggi dibanding jenis lainya, khususnya pada jalur 1 dengan nilai 0,9493. Sementara Indeks kelimpahan jenis terendah terdapat pada jenis Engkabang Bukit (Shorea pinangaScheff.), yaitu pada jalur pengamatan 2 dengan nilai 0,5764.

\section{Kesimpulan}

1. Hutan Adat Gunung SokaDusun Padang Sebantik Kecamatan Air Besar Kabupaten Landakditemukan sedikitnya ada 23 jenis vegetasi pohon yang terdiri dari 13 family dengan total individu sebanyak 741 pohon.Secara Keseluruhan, tegakan di areal penelitian vegetasi pohon terbesar yaitu pada jenis engkabang bukit (Shorea pinangaScheff.) dan terendah pada jenis keraci (Quercus lucida Roxb.)

2. Kawasan Hutan Adat Gunung Soka menunjukan bahwa keanekaragaman jenis pada masing-masing jalurmemiliki nilai mendekati 1 . Hal ini menunjukan bahwa pada kawasan tersebut memiliki keanekaragaman jenis yangmasih tinggi dan menyimpan plasma nuftah yang beragam.

3. Adanya beberapa jenis tingkat pohon yang menurut IUCN masuk dalam Red List of Threatned, yaitu pulai (Alstonia scholaris(L.) R. Br.) masuk dalam kategori hampir terancam (Least concern), artinya berada dalam keterancaman atau mendekati ancaman kepunahan namun tidak masuk ke status terancam atau hampir terancam, dan gaharu (Aquilaria malaccensisLam.) masuk dalam kategori rawan (Vulnerable), artinya menghadapi resiko punah di alam liar di waktu mendatang. 


\section{Saran}

1. Kerusakan hutan Adat gunung SokaDusun Padang Sebantik Kecamatan Air Besar dapat terjadi karena beberapa faktor, diantaranya penebangan liar dan kebakaran hutan, sehingga perlu dilakukan pengontrolan secara aktif dari masyarakat sekitar (lokal) beserta para pemangku adat, untuk menjaga keanekaragaman jenis yang ada di dalamnya.

2. Perlu dilakukan penelitian lanjutan tentang pengembangan jenis untuk di jadikan pohon benih serta peluang budi daya pohon hutan.

\section{DAFTAR PUSTAKA}

Alhani, F, Togar Fernando M, Herlina Darwati. 2015. Keanekaragaman jenis vegetasi pohon di kawasan hutan dengan tujuan khusus ( KHDTK ) Samboja kabupaten Kutai Kartanegara Kalimantan Timur. Jurnal Hutan Lestari Vol. 3 ( 4 ) : 590-598.

Agustian. 2014. Analisa Vegetasi Tegakan Hutan di areal hutan kota Gunung Sari kota Singkawang. Jurnal Hutan Lestari Vol. 3 (2) : 217-226.

Anonim.2013. Mengenal Istilah Kepunahan dan Status Konservasi IUCN. (www.satwa.net/136/mengenal istilah kepunahan dan status konservasi IUCN)

[12 Mei 2017].

Indriyanto.2006.Ekologi Hutan. Jakarta :Bumi Aksara.

Indriyanto. 2009. Struktur dan Keanekaragaman Flora pada Komunitas Hutan yang Dikelola petani dalam Register 19 Provinsi Lampung. Tesis. Jurusan Kehutanan Fakultas Pertanian Universitas Lampung.( tidak dipublikasikan )

Nita, H. Keanekaragaman Vegetasi Pada Hutan Adat Penganjik Desa Sahan Kecamatan Seluas Kabupaten Bengkayang. Skripsi. Fakultas Kehutanan Universitas Tanjungpura Pontianak. (tidak dipublikasikan).

Soerianegara., I., dan A. Indrawan 1978. Ekologi Hutan Indonesia. Bogor:Departemen Manajemen Hutan, Fakultas Kehutanan IPB.

Soerianegara., I., dan A. Indrawan 1988. Ekologi Hutan Indonesia. Bogor : Laboratorium Ekologi Hutan, Fakultas Kehutanan IPB.

Undang-Undang Republik Indonesia Nomor 41 Tahun 1999. Jakarta: Ketentuan Pokok Kehutanan. Depertemen Kehutanan dan Perkebunan. 